\title{
CORRECTIONS
}

\section{Author Correction: Adaptive platform trials: definition, design, conduct and reporting considerations}

The Adaptive Platform Trials Coalition

Nature Reviews Drug Discovery (2019) https://doi.org/10.1038/s41573-019-0034-3 Published online 28 August 2019

The name of an author, Alex John London, has been corrected.

https://doi.org/10.1038/s41573-019-0045-0 I Published online 10 September 2019 